\title{
Copa do Mundo 2014: uma abordagem pedagógica sobre o seu legado
}

\author{
World Cup 2014: A Pedagogical Approach on your Legacy
}

\author{
Amarildo da Silva Araujo \\ Rede Municipal de Santa Luzia/MG/Brasil \\ Mestre em Estudos do Lazer, Universidade Federal de Minas Gerais \\ asabhz@gmail.com
}

\begin{abstract}
RESumo: A realização do megaevento da Copa do Mundo da FIFA Brasil 2014 trouxe mudanças nas cidades-sedes e produziu impactos em diversos campos como: economia, política, organização espacial, dentre outros. A educação não ficou alheia a esse quadro, visto que a Copa atingiu as pessoas independente delas serem torcedoras ou não e também chegou às instituições escolares. Assim, este estudo teve como objetivo analisar a opinião dos professores sobre o legado do megaevento de lazer da Copa do Mundo FIFA Brasil 2014 em uma escola pública de Belo Horizonte/MG. Foi realizado o estudo de caso com utilização de entrevista. Os resultados mostraram que para os docentes esse megaevento de lazer envolveu o legado para a educação e cultura se desdobrando para a formação dos alunos e o esporte, e também a negação desse legado com efeitos na perspectiva econômica e social.
\end{abstract}

Palavras Chave: Copa do Mundo da FIFA Brasil 2014; Megaeventos; Educação; Lazer.

ABSTRACT: The mega-event of the 2014 FIFA World Cup Brazil brought changes in host cities and produced impacts in several fields such as: economy, politics, spatial organization, among others. Education was no stranger to this scenario, as the World Cup hit people regardless of whether they were fans or not and also reached school institutions. The purpose of this study was to analyze teachers' opinions about the legacy of the mega-leisure event of the 2014 FIFA World Cup Brazil in a public school in Belo Horizonte/MG. A case study was conducted using interview. The results showed that for the teachers this mega-event of leisure involved the legacy for education and culture, unfolding for the formation of the students and the sport, and also the denial of this legacy with effects from the economic and social perspective.

KEYwoRDS: FIFA World Cup Brazil 2014; Megaeventos; Education; Leisure. 


\section{INTRODUÇÃO}

O futebol, como fenômeno social no Brasil, constitui-se em um dos maiores representantes da cultura brasileira, dialogando com diferentes campos da sociedade, sendo considerado um dos principais elementos de identidade nacional. Para grande parte da nossa população é um referencial de lazer, e quanto aos praticantes dessa modalidade (jogador) ${ }^{1}$ e ao espectador (torcedor ou assistente), ${ }^{2}$ esse esporte se legitima na perspectiva do lazer, criando formas de sociabilidade no cotidiano das pessoas.

Esse esporte está inserido no cotidiano da sociedade brasileira, através das múltiplas práticas (o jogo em si), das diferentes manifestações do torcer, dos vínculos criados pelos produtos e negócios, ou por meio de sua inserção em diversos meios de comunicação. É capaz de mobilizar e movimentar a nação brasileira, nos eventos nacionais ordinários, bem como nos torneios internacionais, como se verificou no megaevento da Copa do Mundo da FIFA Brasil 2014 (Copa 2014), que exigiu vultosos investimentos com reformas e construções de estádios e também em obras de infraestrutura pelo país, produzindo impactos na vida das pessoas, independentemente delas serem torcedoras ou não.

Portanto, a realização desse megaevento trouxe mudanças nas cidadessedes e produziu impactos em diversos campos como: economia, política, organização espacial, dentre outros. A educação não ficou ausente desse processo. As instituições escolares também foram atingidas e sofreram uma intervenção generalizada como a alteração do calendário escolar descrito no art. 64 da Lei no 12.663, de 05 de junho de 2012 Lei Geral da Copa.

Segundo Libâneo, Oliveira e Toschi, os acontecimentos contemporâneos (dentre eles, destaco a Copa 2014) afetam a educação escolar de várias maneiras, a saber: modificam objetivos e prioridades da escola; produzem alterações nos interesses, nas necessidades e nos valores escolares; forçam a escola a mudar suas

\footnotetext{
${ }^{1} \mathrm{O}$ jogador neste caso é considerado como aquele praticante que não está exercendo sua atividade profissional.

2 "Assistente" era o termo usado, até, aproximadamente, os anos 1930, para designar aquela pessoa que assistia a uma partida de futebol sem sentimento efetivo de pertencimento ou paixão clubística, tal como ocorre com inúmeros torcedores. Ver mais sobre esse assunto em: Souza Neto. A invenção do torcer em Bello Horizonte.
} 
práticas; e induzem a transformações na atitude do professor e no trabalho docente. ${ }^{3}$ Esses autores reconhecem que os conhecimentos advindos das produções socioculturais que se originam fora da escola interferem de alguma maneira, nas práticas escolares.

Portanto, nas possíveis relações entre a Copa 2014 e a educação, qual o legado deixado pelo o megaevento da Copa 2014 para as instituições educacionais na percepção dos professores? Assim, o objetivo deste estudo foi analisar a opinião dos professores sobre o legado desse megaevento para a educação escolar. Tendo em vista que, se negligenciarmos a existência de vínculos entre esses elementos pode conduzir a uma interpretação que desqualifica a escola como local onde não se discutem questões que afetam o cotidiano da sociedade ou onde não se atribui a elas a devida e/ou merecida importância.

A propósito dessa questão, Bracht e Almeida afirmam que na relação megaeventos esportivos e escola existem zonas de conflito dos códigos e princípios do modelo dominante de esporte com os da instituição escolar. ${ }^{4}$ Sem se render à lógica do sistema esportivo, a escola deve voltar o esporte aos objetivos educacionais, visando promover ampla "alfabetização esportiva” da população. Justificando a lógica do sistema esportivo que predomina fora da escola, Bracht e Almeida consideram que a Copa 2014 apresenta risco renovado de se instrumentalizar o esporte na escola. ${ }^{5} \mathrm{Ou}$ seja, reproduzir, nela, seu formato baseado no rendimento esportivo e na competição.

Madruga defende a realização dos megaeventos com amparo na ideia da relação custo/oportunidade. ${ }^{6}$ Porém, entendemos que esse binômio voltado para a escola pode ser transformado em educação/oportunidade; ou seja: a escola busca se envolver com esse momento histórico e social que a população e o País estão/estavam viven(cian)do e, por meio de ações pedagógicos extrai e constrói a partir do megaevento o máximo de possibilidades educativas.

\footnotetext{
${ }^{3}$ LIBÂNEO; OLIVEIRA; TOSCHI. Educação escolar.

${ }^{4}$ BRACHT; ALMEIDA. Esporte, escola e a tensão que os megaeventos esportivos trazem para a Educação Física escolar.

${ }^{5}$ BRACHT; ALMEIDA. Esporte, escola e a tensão que os megaeventos esportivos trazem para a Educação Física escolar.

${ }^{6}$ MADRUGA. Megaeventos esportivos como gestão de custos oportunidade.
} 
Desse modo, é possível afirmar que o processo educativo dialoga diferentes esferas, como os megaeventos e seus impactos produzidos. A Copa 2014 foi uma entre outras possibilidades de vivência do lazer e de oportunidade para o ambiente escolar refletir sobre essas questões; além disso, desenvolver saberes que sejam significativos para o estudante, para o professor e para a escola.

\section{Metodologia}

Nessa investigação, de abordagem qualitativa, foi realizado o estudo de caso em uma escola da rede pública estadual do município de Belo Horizonte. A escolha da instituição ocorreu por meio de sorteio. Foi investigado um professor por disciplina do ensino médio nos turnos da manhã e noite. Participaram 23 docentes, sendo 12 pelo turno da manhã e 11 para a noite, atuantes no terceiro ano do ensino médio. A coleta dos dados ocorreu nas dependências da escola com a realização de entrevista semiestruturada em novembro de 2013.

Utilizando a análise de conteúdo proposta por Bardin, as falas semelhantes foram agrupadas, em seguida, foram formadas as unidades de significação relacionadas às afinidades atribuídas nas verbalizações de cada sujeito e nomeadas as categorias. ${ }^{7}$ Apesar de que cada fala estar inserida em uma das unidades de significação, ela pode perpassar por outra(s).

\section{FUNDAMENTAÇÃo TEÓRICA}

Algumas cidades buscam, na organização dos megaeventos, a possibilidade de se promoverem mundialmente e de impulsionar o seu desenvolvimento. A tarefa de sediar uma empreitada como a Copa 2014 tornou-se uma alternativa para acelerar a construção de planos de (re)estruturação das cidades e, como consequência, melhorar a qualidade de vida da população. ${ }^{8}$

Assim, a escolha de um país para sediar um megaevento requer, de modo geral, o aporte de vultosos recursos econômicos, além dos montantes usuais nos

\footnotetext{
${ }^{7}$ BARDIN. Análise de conteúdo.

${ }^{8}$ PIRES; BAPTISTA; PORTUGAL. Megaeventos e o desenvolvimento urbano e regional.
} 
orçamentos públicos, e a capacidade de negociação, em diferentes esferas do poder público, para atender os pré-requisitos de um megaevento.

De acordo com Ratton, os megaeventos apresentam duas características principais: as consequências trazidas para as cidades, regiões ou países e a atração da cobertura midiática que eles geram. ${ }^{9}$ Esses megaeventos ocorrem em intervalos temporais maiores do que campeonatos e ligas esportivas habituais, apresentando estrutura e programação de grande porte, bem acima da média dos eventos esportivos nacionais ordinários. Também contam com os meios de comunicação de massa, em suas mais variadas formas, para potencializar a sua comunicação.

Rubio afirma que um megaevento se caracteriza por seu caráter temporal, sua capacidade de atrair um grande número de participantes de diversas nacionalidades e, também, por chamar a atenção dos meios de comunicação, com abrangência e ressonância global. ${ }^{10}$ A propósito da sazonalidade dos megaeventos esportivos, Machado e Rubio afirmam que "são eventos de curto prazo, com duração variável de duas semanas a um mês, com consequência de longo prazo para a localidade que os abriga".11 Destacam, ainda, a exibição das cidades na mídia, durante seu período de realização, de uma forma que jamais conseguiriam atingir.

France e Roche consideram que os megaeventos são utilizados como uma estratégia para a regeneração das cidades onde são realizados, ao demandarem intervenções no espaço e no imaginário urbano. ${ }^{12}$ Para esses autores, os principais instrumentos e veículos de políticas de transformação das cidades, cujas imagens se encontram degradadas, são as criações de atrações turísticas, como a realização de grandes exposições artísticas e a organização de eventos esportivos, ou seja, são atrações voltadas essencialmente para o campo do lazer. Já para Roche:

[...] são eventos de larga escala cultural (incluindo comerciais e esportivos) que tem uma característica dramática, apelo popular massivo e significância internacional. Eles são tipicamente organizados por combinações variáveis de governos nacionais e organizações internacionais não governamentais e ainda podem ser ditos como importantes elementos nas versões "oficiais" da cultura pública. ${ }^{13}$

\footnotetext{
${ }^{9}$ RATTON. Megaeventos esportivos, violência e pânico moral.

${ }^{10}$ RUBIO. Os Jogos Olímpicos e a transformação das cidades.

${ }_{11}$ MACHADO; RUBIO. Legados do esporte, p. 70.

12 FRANCE; ROCHE. Sport mega-events, urban policy and youth identity.

${ }^{13}$ ROCHE. Mega-events and modernity, 1.
} 
Em decorrência da Copa 2014 e dos Jogos Olímpicos 2016, segundo Tavares, os termos "megaevento" e "legado" tornaram-se bem presentes em nosso cotidiano, gerando crescentes debates e investigações. ${ }^{14}$ Esse autor ressalta que os esforços acadêmicos para a conceituação de megaevento, no Brasil, ainda são objeto de importantes discussões.

De modo geral, legado pode ser entendido como o resultado de um determinado acontecimento. Para o governo, a Copa 2014 se constituiu como um catalisador de obras e investimentos, ao dinamizar a economia, fortalecendo, assim, a posição do país no mercado mundial. ${ }^{15}$ Dessa forma, a aceleração das economias locais, as inovações tecnológicas e técnicas demonstram o potencial de impacto desses acontecimentos e, portanto, conduzem a uma imagem positiva do espaço urbano, socialmente atraente e organizado para a recepção dos turistas e a melhoria da qualidade de vida dos moradores, tornando as cidades-sede competitivas e articuladas com os propósitos dos legados desse evento. Conforme o portal da Copa, "a visibilidade obtida pelo Brasil no exterior, impulsionada pela realização da Copa 2014 já trouxe ganhos expressivos no turismo". ${ }^{16}$ Logo, esse megaevento de futebol é instrumento de produção do discurso sobre os legados esportivos, dada a sua projeção local, regional, nacional, continental e mundial.

O legado comumente é visto como um benefício em diversas áreas, trazido por uma intervenção planejada para as cidades que sediam os megaeventos esportivos. Por serem complexos e multidimensionais, esses eventos implicam em contradições e dificuldades, podendo ocorrer um legado negativo. Eles necessitam ter um planejamento comprometido com a população local e estar em consonância com o plano urbano para se tornarem positivos. ${ }^{17}$ Para Rodrigues e Pinto, do ponto de vista social, espera-se que os legados de megaeventos esportivos ao transformarem a estrutura e o cotidiano das cidades beneficiem toda a população. ${ }^{18}$

\footnotetext{
${ }_{14}^{14}$ TAVARES. Megaeventos esportivos.

15 Informações do Governo Federal sobre a Copa 2014 disponíveis em: <http://www.copa2014.gov.br>.

${ }^{16}$ Ver mais sobre esse assunto em: <http://www.copa2014.gov.br>.

17 RODRIGUES; PINTO. Subsídios para pensar os legados de megaeventos esportivos em seus tempos presente, passado e futuro.

${ }^{18}$ RODRIGUES; PINTO. Subsídios para pensar os legados de megaeventos esportivos em seus tempos presente, passado e futuro.
} 
De acordo com Preuss "o legado é a estrutura planejada ou não, positiva ou negativa, tangível ou intangível que foi ou será criada por meio de um evento esportivo e que permanece depois do mesmo". ${ }^{19}$ Sobre a estrutura Preuss, concordo com a observação de Souza e Pappous, que ela corresponde aos elementos que foram criados ou modificados como consequência da realização do megaevento, tais como infraestruturas, desenvolvimento de habilidades e educação, imagem, emoções, redes de interação e valores culturais gerando os legados tangíveis e intangíveis. Os legados tangíveis, por terem maior visibilidade, normalmente assumem maior importância e prioridades quando se trata dos megaeventos. As estruturas, materiais e econômicas são elementos de maior precisão quando se busca medir e avaliar os resultados. Quanto aos legados intangíveis, são imateriais, e há uma dificuldade de aferir com precisão os resultados.

Villano, Silva, Rizzuti, Miragaia e Costa ressaltam que "é necessário se ter em mente a importância do custo-oportunidade". ${ }^{20}$ Eles afirmam que não há lugar para improvisação em megaeventos, por isso, um planejamento consistente pode gerar: “a) legados do evento em si; b) legados da candidatura do evento; c) legados da imagem do Brasil; d) legados de governança; e e) legados de conhecimento". Para Filgueira, o grande desafio que deve pautar e orientar as ações dos nossos dirigentes é a produção de legados que venham a contribuir para a reversão do quadro de injustiça, exclusão e vulnerabilidade social que caracteriza a sociedade brasileira. ${ }^{21}$

Segundo Proni e Silva, os efeitos imediatos de um megaevento esportivo como a Copa do Mundo de futebol e os legados mais duradouros são bastante diferentes entre as nações, devido aos estágios de desenvolvimento econômico diferentes. ${ }^{22}$ Países emergentes requerem mais investimentos em infraestrutura aumentando consideravelmente os riscos e custos de oportunidade, porém, o custo do trabalho é relativamente mais baixo, podendo representar custos operacionais e de infraestrutura menores. Em contrapartida a realização de uma Copa pode canalizar recursos para sanar tais problemas.

\footnotetext{
${ }^{19}$ PREUSS. Lasting effects of major sporting events, p. 3. (Tradução minha).

20 VILLANO; SILVA; RIZZUTI; MIRAGAIA; COSTA. Gestão de legados de megaeventos esportivos, p. 48.

${ }^{21}$ FILGUEIRA. Importância dos legados de megaeventos esportivos para a Política Nacional do Esporte.

${ }^{22}$ PRONI; SILVA. Impactos econômicos da Copa do Mundo de 2014.
} 
No que diz respeito aos diferentes efeitos e demandas dos megaeventos, observa-se que os investimentos educacionais e propostas pedagógicas cujos ganhos são intangíveis e, portanto mais difíceis de serem previstos, por serem de difícil mensuração, passam a depender de muitos fatores para geração de resultados, já que estes não se fazem de imediato. 0 legado pode ser visto como um processo para realização de um evento como o da Copa 2014. Para Bernabé e Starepravo, os megaeventos contribuem para educação, principalmente para a Educação Física, por se tratar de discussões do esporte, práticas corporais e desenvolvimento físico. ${ }^{23}$

Silva também aborda a Educação Física escolar relacionada aos legados de megaeventos esportivos, com destaque para possíveis aspectos positivos e negativos que poderão refletir nessa disciplina. ${ }^{24}$ Com relação aos aspectos positivos dos legados de megaeventos para a Educação Física escolar é enfatizado: 1) aulas que viabilizem aos alunos a produção de novos conhecimentos, visando a parceria dos alunos na ressignificação de temas, com base no conhecimento sistematizado; 2) busca da articulação teoria-prática, da transformação da informação em conhecimento, para que os alunos analisem as mensagens da mídia na formação do espectador sem formatação; 3) aulas em que se tenha possibilidade de debater, refletir e ressignificar o esporte e outras práticas corporais; e 4) a possibilidade de uma educação para o lazer com ênfase no conteúdo físico esportivo que poderá viabilizar para o aluno o acesso a elementos que serão fundamentais em suas opções de lazer durante a vida. Esses aspectos são importantes e devem ser buscados independente de um megaevento, porém o contexto oportuniza tais legados.

A respeito dos possíveis aspectos negativos a autora destaca: 1) a questão da Educação Física escolar reforçar a ideia presente no senso comum de que o esporte é um meio para retirar jovens da rua e do vício, tendo a mídia exacerbando o esporte de alto rendimento como se atingisse todos os jovens; 2) o problema de não haver reflexão sobre as informações difundidas no meio social e de não haver a transformação das mesmas em conhecimento; e 3) o fato da Educação Física

\footnotetext{
${ }^{23}$ BERNABÉ; STAREPRAVO. Megaeventos esportivos.

${ }^{24}$ SILVA. Legados de megaeventos esportivos.
} 
escolar enfatizar os megaeventos esportivos sem levar em conta a realidade dos alunos, sua compreensão inicial e tratar o esporte como o único elemento da cultura corporal de movimento a ser discutido na escola.

Os megaeventos são uma oportunidade de realizar essa discussão em conjunto com a academia. As escolas e os governos devem criar oportunidade para os professores de Educação Física terem acesso aos novos conhecimentos produzidos na área e manter um processo contínuo de formação, gerando mais chances de construção de projeto escolar comprometido com a emancipação dos estudantes. ${ }^{25}$

Daólio se preocupa com a maneira como tem ocorrido a concepção e organização dos megaeventos esportivos no País, para esse autor existe o risco de gerar pessoas passivas que apenas consumam os espetáculos esportivos e os produtos a eles associados predominando o consumismo, sem possibilidade de maiores conhecimentos e, sobretudo, de prática. Também chama a atenção para o papel do professor que deve assumir esse trabalho de esclarecimento com os estudantes. Daólio afirma que:

[...] a tarefa urgente e fundamental da Educação Física escolar: diante do fato de que os megaeventos esportivos estão mesmo acontecendo, os professores da área devem assumir esse tema em suas aulas, não no sentido de reproduzir o ufanismo acrítico propalado pela mídia, mas de estimular junto aos alunos um conhecimento crítico que leve à prática esportiva consciente e transformadora. Como mediadores pedagógicos que são, os professores de Educação Física atualizam significados junto com seus alunos, desconstroem visões de senso comum e reconstroem e ampliam outras formas de compreensão em relação aos conteúdos da área. Nesse sentido é possível esperar que, a partir da mediação da Educação Física escolar, a compreensão e a relação dos alunos com os megaeventos esportivos serão qualificadas. ${ }^{26}$

Considerando a Copa 2014 como um megaevento de lazer e buscando um maior envolvimento das disciplinas escolares, Bracht afirma que as diferentes disciplinas da escola devem contribuir para a educação para o lazer. ${ }^{27}$ Porém, de acordo com a organização dos conhecimentos e práticas escolares a Educação Física e a Educação Artística possuem uma relação mais direta com o lazer, pois

\footnotetext{
${ }^{25}$ SILVA. Legados de megaeventos esportivos.

${ }^{26}$ DAÓLIO. Educação física escolar e megaeventos esportivos, p. 135.

${ }^{27}$ BRACHT. Educação física escolar e lazer.
} 
educam para ele ao transmitir suas práticas que podem ser vivenciadas nessa dimensão da vida. Bracht defende a ideia de que:

[...] não devemos responsabilizar exclusivamente uma ou outra disciplina escolar pela educação para o lazer (a Educação Física e a Educação Artística por exemplo), mas que a escola como um todo, deve assumir a educação para o lazer como tarefa nobre e importante, o que implica em colocar em questão as próprias finalidades sociais da instituição escolar. Isso implicaria em uma razoável mudança naquilo que poderíamos chamar de cultura escolar que, diga-se logo, não envolve apenas os saberes e as práticas escolares, mas também, o tempo e o espaço. ${ }^{28}$

Em uma direção semelhante que busca a relação entre os conhecimentos, Silva, Souza Neto e Campos, ao refletir sobre o lazer na escola, afirmam: "é fundamental e requer urgência o encaminhamento de propostas de ação que contemplem o desenvolvimento e a sistematização de experiências interdisciplinares no âmbito do lazer". ${ }^{29}$ Portanto, podemos identificar a aproximação entre essa tríade: o megaevento da Copa 2014, lazer e educação.

\section{ANÁLISE E DISCUSSÃo DOS DADOS}

Duas categorias foram construídas neste estudo: a denominada de "legado para a educação e cultura" e a segunda "negação do legado para a educação". A primeira foi composta por quatro unidades de significação analisadas na seguinte ordem: legado para a cultura, legado para a formação; legado para a educação e legado para o esporte. A segunda foi constituída pelo legado e negócio e não deixa legado para a educação.

$\mathrm{Na}$ análise da unidade de significação "legado para a cultura", Bracht entende que a cultura que dá sentido e justifica a educação, ${ }^{30}$ o que nos permite pensar em uma forma de educação que não privilegia somente o saber lógico formal presente no conhecimento científico. Esse autor opera com uma ampla noção de cultura, afirmando que a função social da escola é a transmissão de parte do legado cultural da humanidade. Assim, o lazer como um elemento da cultura é

\footnotetext{
${ }^{28}$ BRACHT. Educação física escolar e lazer, p. 164.

${ }^{29}$ SILVA; SOUZA NETO; CAMPOS. Lazer, torcidas e futebol.

${ }^{30}$ BRACHT. Educação física escolar e lazer.
} 
responsabilidade da escola, porque o que justifica o empreendimento educativo é a transmissão e perpetuação da experiência humana como cultura.

\section{Quadro 1 - Categorias estabelecidas para os legados}

\begin{tabular}{|c|c|c|c|}
\hline Aproximação entre as falas dos sujeitos & $\begin{array}{l}\text { Sujeitos / } \\
\text { entrevistas }\end{array}$ & $\begin{array}{l}\text { Unidades de } \\
\text { significação }\end{array}$ & Categoria \\
\hline Os cursos são positivos para educação. & 1,2 e 3 & \multirow{6}{*}{$\begin{array}{l}\text { Legado para } \\
\text { a formação }\end{array}$} & \multirow{16}{*}{$\begin{array}{l}\text { Legado } \\
\text { para a } \\
\text { educação } \\
\text { e cultura }\end{array}$} \\
\hline "Há uma valorização da educação com a Copa". & 4 & & \\
\hline $\begin{array}{l}\text { "A Copa traz mensagem de paz, harmonia, contra } \\
\text { violências e agressões". }\end{array}$ & 2 & & \\
\hline $\begin{array}{l}\text { "O legado é relacionar as dimensões, políticas, } \\
\text { geográficas, sociológicas e econômicas com os } \\
\text { campos do saber". }\end{array}$ & 6 & & \\
\hline $\begin{array}{l}\text { "As manifestações trouxeram mais participação } \\
\text { dos jovens". }\end{array}$ & 9 e 4 & & \\
\hline $\begin{array}{l}\text { "As manifestações mostraram como a população } \\
\text { está insatisfeita". }\end{array}$ & 3 & & \\
\hline $\begin{array}{l}\text { "O futebol mostra o trabalho em equipe } \\
\text { (relacionamento)". }\end{array}$ & 7 & \multirow{4}{*}{$\begin{array}{l}\text { Legado para } \\
\text { o esporte }\end{array}$} & \\
\hline $\begin{array}{l}\text { A Copa traz mais jogos para a Educação Física } \\
\text { (mais esporte). }\end{array}$ & 8 e 9 & & \\
\hline $\begin{array}{l}\text { "O legado pode ficar para o esporte, mas não sei } \\
\text { se fica para a educação". }\end{array}$ & 10 & & \\
\hline $\begin{array}{l}\text { "Ver os jogos de perto mais próximo do real, é ver } \\
\text { o espetáculo". }\end{array}$ & 11 & & \\
\hline "A reflexão para a escola e para o mundo". & 12 & \multirow{2}{*}{$\begin{array}{l}\text { Legado para } \\
\text { a educação }\end{array}$} & \\
\hline $\begin{array}{l}\text { "Reflexão sobre o sentido de ser um cidadão } \\
\text { brasileiro". }\end{array}$ & 13 & & \\
\hline Aproximação dos alunos com outras culturas. & $\begin{array}{c}14,15,16 \\
17 \text { e } 18\end{array}$ & \multirow{4}{*}{$\begin{array}{l}\text { Legado para } \\
\text { a cultura }\end{array}$} & \\
\hline $\begin{array}{l}\text { "Vai trazer um conhecimento e uma boa } \\
\text { experiência". }\end{array}$ & 19 & & \\
\hline É um evento enorme, de grande riqueza cultural. & 20 & & \\
\hline $\begin{array}{l}\text { A experiência que os brasileiros vão ganhar vai } \\
\text { trazer melhorias para cada pessoa. }\end{array}$ & 21 e 5 & & \\
\hline $\begin{array}{l}\text { "Não vai deixar nada nem para a educação e nem } \\
\text { para escola". }\end{array}$ & 23 & \multirow{3}{*}{$\begin{array}{l}\text { Não deixa } \\
\text { legado para } \\
\text { a educação }\end{array}$} & \multirow{4}{*}{$\begin{array}{c}\text { Negação } \\
\text { do } \\
\text { legado } \\
\text { para a } \\
\text { educação }\end{array}$} \\
\hline $\begin{array}{l}\text { Não vejo herança para a educação e não é do } \\
\text { ponto de vista do pedagógico. }\end{array}$ & 22 e 18 & & \\
\hline $\begin{array}{l}\text { "Não há investimentos no esporte na própria } \\
\text { escola". }\end{array}$ & 20 & & \\
\hline $\begin{array}{l}\text { "É um evento mais comercial que educativo. Não é } \\
\text { para a educação, parece ser publicitário e } \\
\text { comercial. Não se sabe se ideologicamente há } \\
\text { ensinamentos, é mais comercial que cultural. O } \\
\text { foco é o comércio, a mercadoria, é a marca, vitrine. } \\
\text { Somos mercadoria". }\end{array}$ & 5 & $\begin{array}{l}\text { Legado e } \\
\text { negócio }\end{array}$ & \\
\hline
\end{tabular}

Fonte: Autor da pesquisa. 
Segundo Silva, a escola deve ser um espaço de troca de conhecimentos que são historicamente construídos ao longo do tempo e precisa estar aberta a novos saberes que são elaborados permanentemente pela sociedade. ${ }^{31} \mathrm{Um}$ megaevento como da Copa 2014 pode ser entendido como exemplo dessas trocas de conhecimentos, que na visão de Damo ocorrem no campo simbólico com forte apelo para a sua realização. ${ }^{32}$

De acordo com entendimento de alguns participantes, esse megaevento poderia trazer como legado a "aproximação dos alunos com outras culturas", conforme as entrevistas 14, 15, 16, 17 e 18, pelo fato de ser "um evento enorme, de grande riqueza cultural" segundo o sujeito 20, e "vai trazer um conhecimento e uma boa experiência", de acordo com o relato 19.

As respostas indicam que o legado da Copa 2014 poderia ser uma oportunidade da escola ser um veículo de transmissão de cultura para o estudante conhecer e aproximar das pessoas de outras nacionalidades, percebendo que as diferenças com os outros mostram a diversidade como uma riqueza cultural. Daólio ao afirmar que:

[...] um costume ou uma prática de um determinado grupo não devem ser vistos como certos ou errados, melhores ou piores do que outros do nosso próprio grupo. Ambos têm significados próprios que os justificam no grupo no qual ocorrem. Portanto, a diferença não deve ser pensada como inferioridade. 0 que caracteriza a espécie humana é justamente sua capacidade de se expressar diferenciadamente. Porque os homens são iguais justamente pela expressão de suas diferenças. ${ }^{33}$

Com relação a educação e a cultura, Forquin ressalta que a cultura escolar se refere aos acontecimentos intencionalmente trabalhados na escola. ${ }^{34}$ De acordo com esse autor, "educar, ensinar é colocar alguém em presença de certos elementos da cultura a fim de que deles se nutra, que os incorpore à sua substância, que ele construa a sua identidade intelectual e pessoal". ${ }^{35}$ Então, a aproximação dos elementos da cultura (o lazer, o futebol e a Copa 2014)

\footnotetext{
${ }^{31}$ SILVA. Legados de megaeventos esportivos.

${ }^{32}$ DAMO. O simbólico e o econômico no futebol de espetáculo.

${ }^{33}$ DAÓLIO. Da cultura do corpo, p. 100.

${ }^{34}$ FORQUIN. Escola e cultura.

${ }^{35}$ FORQUIN. Escola e cultura, p. 168.
} 
articulados com projetos desenvolvidos pela escola consiste em uma forma contextualizada para se educar.

Dessa forma, Rubio considera que a realização de um megaevento esportivo pode representar um momento oportuno para alavancar a discussão a respeito do multiculturalismo, pela sua capacidade de estabelecer na escola o reconhecimento de igualdade dos povos, a negação da intolerância e a prática da compreensão. Logo, os megaeventos são considerados um "campo fértil de investigação de relações sociais complexas e paradoxais da sociedade moderna". ${ }^{36}$

As entrevistas dos sujeitos 21 e 5 referem-se "a experiência que os brasileiros vão ganhar vai trazer melhorias para cada pessoa". Essa afirmação "determinista" parece estar em discordância com Forquin e Bracht, que propõe uma relação crítica com a cultura em suas várias manifestações. Entendo que a subjetividade de cada experiência atinge os indivíduos de forma e intensidade diferentes, não podendo ser universalizada a ideia que "vai trazer melhoria para cada pessoa".

Sobre o legado para a formação, para Dantas Junior o esporte tem uma finalidade formativa, voltada para humanizar o sujeito e não excluí-lo ou animalizá-lo. ${ }^{37}$ Ainda Dantas Junior, questiona "o que podem os megaeventos esportivos acrescentar à formação das crianças e jovens brasileiros? Sobretudo, como a escola, já por demais espetacularizada, e a Educação Física se inserem nesse debate?"38 Esse autor traz uma contribuição importante, questionando a ação formativa dos megaeventos.

As entrevistas a seguir se inserem na ideia do legado para a formação. São elas:

"os cursos são positivos para educação" (Sujeitos 1, 2 e 3);

"a valorização da educação" (Sujeito 4);

"a Copa traz mensagem de paz, harmonia, contra violências e agressões" (Sujeito 2);

"o legado é relacionar as dimensões políticas, geográficas, sociológicas e econômicas com os campos do saber" (Sujeito 6);

"as manifestações trouxeram mais participação dos jovens" (Sujeitos 9 e 4); e "as manifestações mostraram como a população está insatisfeita" (Sujeito 3).

\footnotetext{
${ }^{36}$ ALMEIDA; MEZZADRI; MARCHI JÚNIOR. Considerações sociais e simbólicas sobre sedes de megaeventos esportivos, p. 181.

${ }^{37}$ DANTAS JUNIOR. Espetacularização da escola.

${ }^{38}$ DANTAS JUNIOR. Espetacularização da escola, p. 34.
} 
Assim, o legado aparece por meio de ações formativas que possam ser significativas para os professores. Libâneo nos diz que a escola:

[...] é aquela que assegura a todos a formação cultural científica para a vida pessoal, profissional e cidadã, possibilitando uma relação autônoma, crítica e construtiva com a cultura em suas várias manifestações: a cultura promovida pela ciência, pela técnica, pela estética, pela ética, bem como pela cultura paralela (meios de comunicação de massa) e pela cultura cotidiana. ${ }^{39}$

A formação cultural ocorreu também com a participação dos alunos nos protestos nas ruas reivindicando transparência e participação nas decisões do País. Durante a Copa das Confederações em 2013 ocorreu um grande número de protestos pelo país, sendo muitos deles com confronto entre os manifestantes e a segurança policial. As manifestações tinham intenções, intensidades e reivindicação distintas, porém uma pauta comum foi à organização da Copa 2014, seus custos, seus legados e também a ingerência da FIFA no país e nas cidades-sede.

Os relatos dos entrevistados 9 e 4 "as manifestações trouxeram mais participação dos jovens"; e 3 "as manifestações mostraram como a população está insatisfeita". A escola pesquisada se organizou e participou dos protestos. ${ }^{40}$ Essa ação estimulada pelo corpo docente contribuiu para a formação dos estudantes que vivenciaram uma experiência concreta como forma de manifestar os seus direitos como cidadãos.

Pinto considera que o conhecimento é o centro na relação lazer e educação como processo/produto de formação humana que promove não só o domínio de conhecimentos específicos sobre o lazer como também de competências e habilidades adequadas a formação/atuação política, ética e estética. ${ }^{41}$ Dessa forma, o lazer no processo educativo adquire um papel que está na base da formação humana.

Quanto ao legado para a educação, a fala do Sujeito 6, a afirmação que o legado da Copa 2014 estaria em "relacionar as dimensões, políticas, geográficas, sociológicas e econômicas com os campos do saber". Ou seja, esse entrevistado traz

\footnotetext{
${ }^{39}$ LIBÂNEO. Adeus professor, adeus professora?, p. 7.

40 Alguns professores se organizaram com alunos e foram para as ruas, mostrando que a escola estava presente nas manifestações.

${ }^{41}$ PINTO. Lazer e educação.
} 
para a escola o megaevento numa perspectiva educativa dentro de uma abordagem multidisciplinar como considera Bracht. ${ }^{42}$ Silva propõe que as aulas devem propiciar o debate, a reflexão e a ressignificação do esporte e transformar a informação midiática em conhecimento. A escola como um espaço de reflexão é condição de possibilidade para problematizar e estabelecer suas análises e também o legado de forma independente e autônoma. ${ }^{43}$

As entrevistas 12, "a reflexão para a escola e para o mundo", e 13, "a reflexão sobre o sentido de ser um cidadão brasileiro", revelam que a Copa 2014 traz o "legado da reflexão" para a escola, portanto são os atores da própria escola que estão refletindo sobre aquilo que pode ser o seu legado. Se esse evento apresenta a possibilidade de reflexões no ambiente escolar, sinaliza que a instituição pode se apropriar dos legados educacionais que emergem desse contexto, uma vez que possui autonomia para problematizá-lo e construí-lo.

\section{Marcellino, ${ }^{44}$ Daólio,,5 Mascarenhas, ${ }^{46}$ Bracht,47 Melo, ${ }^{48}$ Pinto, ${ }^{49}$ Silva,,50} Dantas Junior ${ }^{51}$ e Silva e Campos ${ }^{52}$ são autores que mesmo com as suas diferentes concepções e propostas autônomas no campo do lazer e da educação apresentaram um traço em comum, que é a necessidade da reflexão do sujeito sobre os contextos sociais que estão envolvidos e a constante busca do desenvolvimento do espírito crítico. Ao considerar essa ideia encontrada em todos esses autores penso que a problematização é o legado desse megaevento para a educação.

Portanto, o legado da Copa 2014 para a educação pode e deve ser elaborado pela própria escola. Problematizar múltiplos aspectos desse megaevento esportivo possibilita identificar e analisar os diferentes pontos de vistas sobre esse acontecimento. A partir das problematizações poderão surgir os diversos olhares

\footnotetext{
${ }^{42}$ BRACHT. Educação física escolar e lazer.

43 SILVA. Legados de megaeventos esportivos.

44 MARCELLINO. Pedagogia da animação.

${ }^{45}$ DAÓLIO. Da cultura do corpo.

46 MASCARENHAS. Lazer como prática da liberdades; MASCARENHAS. Políticas sociais, lazer e educação.

47 BRACHT. Educação física escolar e lazer.

${ }^{48}$ MELO. A animação cultural; MELO. Verbete Lúdico.

${ }^{49}$ PINTO. Lazer e educação.

50 SILVA. Legados de megaeventos esportivos.

51 DANTAS JUNIOR. Espetacularização da escola.

52 SILVA; CAMPOS. Futebol e Educação Física na escola.
} 
sobre esse legado, apontando os pontos positivos e negativos que o envolve. Dessa forma, defendo que o maior legado para a educação desse megaevento está na sua capacidade de aprofundar na problematização sobre a Copa 2014 e isso constitui em um papel da escola.

Entretanto, se defendo a problematização, já problematizo que os aspectos apontados por Silva, afirmando a existência de possíveis legados positivos e negativos para a Educação Física escolar, 53 podem ser pensados que, de fato, não é necessário ter uma Copa do Mundo de futebol para se considerar os aspectos reflexivos apontados pela autora como possíveis legados, pois esses aspectos devem fazer parte "do cotidiano" das aulas. De fato deve estar inserido no dia a dia, mas penso que a Copa 2014 não foi um fato do cotidiano e não é um evento como os ordinários (campeonatos estaduais e nacional), foi um megaevento extraordinário pela sua dimensão e complexidade que merecia uma diretriz educacional oficial para as unidades escolares com vistas a tratar a Copa 2014 pedagogicamente, tomando como referência a relação da educação/oportunidade, pois envolveu a sociedade brasileira e apresentou a possibilidade de vários legados dentre eles para a educação. 0 diferencial está em todo o contexto, nos diferentes impactos e na repercussão desse megaevento. Dessa forma, essa discussão evidencia a dificuldade de se determinar o legado pela sua intangibilidade, mostrando que os legados para a educação são alvo de polêmicas.

O legado para a educação, que em muitos casos são proclamados por indivíduos que desconhecem o cotidiano da escola. Para isso, Paulo Freire menciona que a reflexão crítica se torna uma exigência para a compreensão da realidade de forma autônoma. ${ }^{54}$ Dessa forma, uma educação que busca na autonomia, uma forma de intervenção no mundo com liberdade e consciência nas decisões e nos diálogos, incorpora esses elementos nas ações educativas pelo e para o lazer. Logo, a escola é a instituição legítima para estabelecer qual o legado para a educação advindo da Copa 2014.

Sobre o legado para o esporte, de acordo com as entrevistas 8 e 9, "a Copa traz mais jogos para a Educação Física (mais esporte)". Se aderirmos à lógica

\footnotetext{
${ }_{54}^{53}$ SILVA. Legados de megaeventos esportivos.

${ }^{54}$ FREIRE. Pedagogia da autonomia.
} 
hegemônica do esporte fora da escola corre-se o risco de aplicarmos o esporte de rendimento aos estudantes. Bracht e Almeida nos alertam para o ímpeto de adotarmos a lógica do esporte dos megaeventos como o esporte da escola. 55 Os educandários são instituições com códigos, princípios, valores e interesses voltados aos objetivos educacionais, enquanto o esporte de rendimento prima pela vitória, pelo lucro, pela supremacia e pelo espetáculo.

Mascarenhas, em relação aos megaeventos e à Educação Física escolar, considera negativa a retomada da ideia de pirâmide esportiva e chama a atenção para os perigos em relação à perda do projeto político pedagógico da Educação Física para o esporte de rendimento, pois

[...] há de se dizer que os objetivos da Educação Física devem ser os objetivos da escola e não de políticas e interesses transitórios e externos à sua realidade, como o demandado pelos megaeventos esportivos, em especial, pelo projeto olímpico. Deste modo, o esporte não pode ser confundido com Educação Física, mas deve ser compreendido apenas como um dos seus elementos, junto com a ginástica, o jogo, a dança, a luta, dentre outras práticas corporais produzidas pela humanidade. 56

O legado da Copa 2014 segundo a entrevista 11, é "ver os jogos de perto mais próximo do real, é ver o espetáculo". A ideia de espetáculo pode ser encontrada em Debord, “o espetáculo é o capital em alto grau de acumulação que se torna imagem". ${ }^{57}$ Esse autor é um crítico do capital e apresenta como elemento central de sua teoria a alienação que está para além de uma descrição de emoções. É o modo de organização social no capitalismo que assume novas formas e conteúdos em seu processo de coisificação da vida humana.

Os Sujeitos das entrevistas 7 e 10 afirmam, respectivamente, que "o futebol mostra o trabalho em equipe (relacionamento)" e "o legado pode ficar para o esporte, mas não sei se ficará para a educação". A esse respeito Silva destaca o papel da escola, em especial, das aulas de Educação Física com a possibilidade de debater,

\footnotetext{
${ }^{55}$ BRACHT; ALMEIDA. Esporte, escola e a tensão que os megaeventos esportivos trazem para a Educação Física Escolar.

${ }^{56}$ MASCARENHAS. Megaeventos esportivos e educação física, p. 60.

${ }^{57}$ DEBORD. A sociedade do espetáculo, p. 14.
} 
refletir e ressignificar o esporte e demais práticas culturais. ${ }^{58}$ Assim, as ações e os legados podem deixar ganhos e perdas a partir da reflexão que se constrói.

A segunda categoria de negação do legado para a educação constitui-se em um contraponto com a categoria educação e cultura. Enquanto a primeira categoria analisada afirma que existem legados para a educação, a segunda estabelece que a Copa 2014 não apresentou legado algum no campo da educação escolar.

A Copa 2014 "não vai deixar nada nem para a educação e nem para escola" (entrevista 23) e "não vejo herança para a educação e não é do ponto de vista do pedagógico" (entrevista 22 e 18). Essas falas negam um legado para a educação advindo da Copa 2014.

O Sujeito 20 relata que "não há investimentos no esporte na própria escola". De fato a fala 20 revela um quadro que pode ser constatado na rede pública estadual. Além disso, não é raro encontrar as aulas de Educação Física sendo compreendidas apenas como esporte, não considerando a ginástica, o jogo (brincadeiras), a dança, a luta, dentre outras práticas corporais produzidas ao longo história. Retomo a ideia: "os objetivos da Educação Física devem ser os objetivos da escola e não de políticas e interesses transitórios e externos à sua realidade, como o demandado pelos megaeventos esportivos". ${ }^{9}$ Portanto, há um disparate entre o esporte hegemônico que é apresentado pela mídia e a precariedade dos investimentos destinados ao esporte escolar.

O Sujeito entrevistado 5 nos diz que a Copa do Mundo de Futebol

[...] é um evento mais comercial que educativo. Não é para a educação, parece ser publicitário e comercial. Não se sabe se ideologicamente há ensinamentos, é mais comercial que cultural. 0 foco é o comércio, a mercadoria, é a marca, vitrine. Somos mercadoria.

Essa fala nos coloca como reféns de um sistema econômico. Porém, dialogo com a ideia de Mascarenhas, que acredita ser possível buscar mudanças para enfrentar a condição de dominação que os grupos hegemônicos nos impõem,

\footnotetext{
58 SILVA. Legados de megaeventos esportivos.

${ }^{59}$ MASCARENHAS. Megaeventos esportivos e educação física, p. 60.
} 
através da intervenção nas organizações populares ao utilizar o lazer como instrumento de educação cidadã, buscando humanizar essa lógica da mercadoria. 60

As cidades também parecem ser atingidas pela lógica da mercadoria. As cidades-sede sofreram mudanças para atender prioritariamente às demandas turísticas, e também às exigências da FIFA (assim como seus patrocinadores). As transformações readequaram as cidades para que proporcionassem maior conforto e uma melhor circulação dos turistas quanto aos pontos a serem visitados, de forma a privilegiar as imagens dos patrocinadores do evento que possuem interesse em dar visibilidade global em seus produtos. ${ }^{61}$

A respeito do caráter econômico citado na entrevista 5, não restam dúvidas de que o megaevento da Copa 2014 se transformou nas últimas quatro edições em um lucrativo negócio, evidenciando um ganho econômico para a FIFA e deixando a expectativa de muitos ganhos para a cidade. Além de comercializar as imagens com a televisão, acrescenta-se aos ganhos a venda de ingressos para os jogos, os patrocinadores e o fato da FIFA não custear as construções e reformas nos estádios, além das obras de infraestrutura exigidas para o evento. Portanto, nada mais justo que diante de tantas exigências de investimento feitas pela FIFA, houvesse um retorno para a educação num país que notoriamente carece de investimentos maciços nessa área.

Assim, a Copa 2014 apresentou uma expectativa positiva sobre o legado econômico reconhecido principalmente pelos governos envolvidos, sobretudo com as obras e os empregos temporários, e também para os grupos empresariais que se beneficiaram com o evento. Vale lembrar, que restam por todo País uma série de obras equivocadas e/ou inacabadas, evidenciando o desperdício do dinheiro público. Além disso, esse estudo constituiu em uma contribuição para pensar o legado desse megaevento para a educação que ficou aquém das suas possibilidades.

\footnotetext{
${ }^{60}$ MASCARENHAS. Lazer como prática da liberdades; MASCARENHAS. Políticas sociais, lazer e educação.

${ }^{61}$ GONÇALVES. A lógica do "elefante branco".
} 


\section{CONSIDERAÇões FinAIS}

Os legados que envolvem uma Copa do Mundo de futebol podem ser tangíveis ou intangíveis. De modo geral, os tangíveis por terem maior visibilidade assumem maior importância e prioridades quando se trata dos megaeventos. As estruturas, materiais e econômicas são elementos de maior precisão e percepção quando se busca medir e avaliar os resultados. Quanto aos legados intangíveis, são imateriais, e há uma dificuldade de aferir com precisão os resultados. Neste estudo, a intangibilidade dos legados da Copa 2014 para a educação mostrou a complexidade em se tratar desse assunto no campo educacional, devido à imaterialidade dos mesmos.

No propósito de saber dos entrevistados se a Copa 2014 deixaria algum legado para a educação foram construídas duas categorias. A primeira de legados para a educação e cultura que envolveu também a intervenção na formação dos alunos e para o esporte. Por meio dessa categoria, foi abordada a questão da escola como um espaço de reflexão, ao problematizar esse megaevento, ou seja, os sujeitos da própria instituição escolar estariam estabelecendo o legado para a educação, construindo de forma autônoma o seu próprio legado.

A segunda categoria recebeu a denominação de negação do legado para a educação. Essa categoria encontrou-se fundamentada em negar que há legados para a educação ao ignorar a possibilidade de intervenção pedagógica, demonstrando que esse megaevento apontou um caráter econômico e comercial. Porém, baseado na primeira categoria (legado para a educação e cultura), os argumentos construídos e apresentados demonstraram um forte indício na existência do legado para a educação. No entanto, não é possível negar a finalidade econômica, comercial e os múltiplos interesses na realização da Copa 2014. 


\section{REFERÊNCIAS}

ALMEIDA, Bárbara Schausteck de; MEZZADRI, Fernando Marinho; MARCHI JÚNIOR, Wanderley. Considerações sociais e simbólicas sobre sedes de megaeventos esportivos. Motrivivência, ano XXI, n. 32/33, p. 178-192, jun.dez. 2009.

BARDIN, Laurence. Análise de conteúdo. Lisboa: Edições 70, 1979.

BERNABÉ, Andressa Peloi; STAREPRAVO, Fernando Augusto. Megaeventos esportivos: o desenvolvimento do legado esportivo educacional. Pensar a Prática, v. 17, n. 2, p. 456-471, jan.-mar. 2014.

BRACHT, Valter; ALMEIDA, Felipe Quintão de. Esporte, escola e a tensão que os megaeventos esportivos trazem para a Educação Física escolar. Em Aberto, v. 26, n. 89, p. 133-145, jan.-jun. 2013.

BRACHT, Valter. Educação física escolar e lazer. In: WERNECK, Christiane Lucce Gomes; ISAYAMA, Helder Ferreira. (Org.). Lazer, recreação e Educação Física. Belo Horizonte: Autêntica, v. 1, 2003, p. 147 -172.

BRASIL. Lei no 12.663, de 05 de Junho de 2012. Dispõe sobre as medidas relativas à Copa das Confederações FIFA 2013, à Copa do Mundo FIFA 2014 e à Jornada Mundial da Juventude - 2013. Disponível em: <https://goo.gl/7WnjuB>. Acesso em: 17 jan. 2018.

DAMO, Arlei Sander. O simbólico e o econômico no futebol de espetáculo: as estratégias da FIFA para tornar as Copas lucrativas a partir de uma interpretação antropológica. Razón y Palabra, n. 69, p.1-35, jun.-ago. 2009.

DANTAS JUNIOR, Hamilcar Silveira. Espetacularização da escola: a Educação Física, o esporte e os megaeventos esportivos. Em Aberto, v. 26, n. 89, p. 3546, jan.-jun. 2013.

DAÓLIO, Jocimar. Educação Física escolar e megaeventos esportivos: desafios e possibilidade. Revista Kinesis, v. 31, n. 1, p. 125-137, jan.-jun. 2013.

DAÓLIO, Jocimar. Da cultura do corpo. Campinas: Papirus. 1995.

DEBORD, Guy. A sociedade do espetáculo. 4. ed. Rio de Janeiro: Contraponto, 1997.

FILGUEIRA, Julio Cesar Monzú. Importância dos legados de megaeventos esportivos para a Política Nacional do Esporte: cidade, cidadania e direitos dos cidadãos. In: RODRIGUES, Rejane Penna et al. (Org.). Legados de megaeventos esportivos. Brasília: Ministério do Esporte, 2008, p. 65-73.

FORQUIN, Jean-Claude. Escola e cultura: as bases sociais e epistemológicas do conhecimento escolar. Porto Alegre: Artes Médicas, 1993.

FRANCE, A.; ROCHE, Maurice. Sport mega-events, urban policy and youth identity: sigues of citizenship and exclusion in Sheffield. In.: Maurice Roche (ed.) Sport, Popular Culture and Identity. Aachen: Meyer \& Meyer, 1998.

FREIRE, Paulo. Pedagogia da autonomia: saberes necessários à prática educativa. São Paulo: Paz e Terra, 1996. (Coleção Leitura). 
GONÇALVES, Glauco Roberto. A lógica do "elefante branco": obsolescência programada do espaço na Copa de 2014. Ateliê Geográfico, v. 7, n. 3, p. 240256, dez. 2013.

LIBÂNEO, José Carlos. Adeus professor, adeus professora?: novas exigências educacionais e profissão docente.6.ed. São Paulo: Cortez, 2002. (Questões da nossa época; v. 67).

LIBÂNEO, José Carlos; OLIVEIRA, João Ferreira de; TOSCHI, Mirza Seabra. Educação escolar: políticas, estrutura e organização. 6. ed. São Paulo: Cortez, 2008. (Coleção Docência em Formação, Saberes Pedagógicos).

MACHADO, Raoni; RUBIO, Katia. Legados do esporte: atleta, cultura e educação. In: MARCELLINO, Nelson Carvalho. (Org.). Legados de megaeventos esportivos. Campinas: Papirus, 2013. (Coleção Fazer/Lazer).

MADRUGA, Djan. Megaeventos esportivos como gestão de custos oportunidades. In: RODRIGUES, Rejane Penna et al. (Org.). Legados de megaeventos esportivos. Brasília: Ministério do Esporte, 2008, p. 59-64.

MARCELLINO, Nelson Carvalho. Pedagogia da animação. Campinas: Papirus, 1990.

MASCARENHAS, Fernando. Megaeventos esportivos e Educação Física: alerta de tsunami. Revista Movimento, v. 18, n. 1, p. 39-67, jan.-mar. 2012.

MASCARENHAS, Fernando. Políticas sociais, lazer e educação: apontamentos para uma pedagogia crítica. Revista Corpo Consciência, v. 11, n. 2, p. 2-9, jul.-dez. 2007.

MASCARENHAS, Fernando. Lazer como prática da liberdade: uma proposta educativa para a juventude. Goiânia: Editora UFG, 2004.

MELO, Victor Andrade de. A animação cultural: conceitos e propostas Campinas: Papirus, 2006.

MELO, Victor Andrade de. Verbete Lúdico. In: GOMES, Christiane. Lucce. (Org.). Dicionário crítico do lazer. Belo Horizonte: Autêntica Editora, 2004, p. 12-15.

PINTO, Leila Mirtes Santos de Magalhães. Lazer e educação: desafios da atualidade. In: MARCELLINO, Nelson Carvalho (Org.). Lazer e sociedade: múltiplas relações Lazer e sociedade: algumas reflexões. São Paulo: Alínea, 2008, p. 45-61.

PIRES, Luciana Santos; BAPTISTA, Luana Fernanda da Silva; PORTUGAL, Licínio da Silva. Megaeventos e o desenvolvimento urbano e regional: uma análise das especificidades e impactos proveniente dos jogos olímpicos e um panorama para a cidade do Rio de Janeiro. Revista Brasileira de Estudos Urbanos e Regionais, Anpur, 2013.

PREUSS, Holger. Lasting effects of major sporting events. Institute of Sport Science, Germany, 2006.

PRONI, Marcelo Weishaupt; SILVA, Leonardo Oliveira da. Impactos econômicos da Copa do Mundo de 2014: projeções superestimadas. Texto para Discussão. IE/UNICAMP, Campinas, n. 211, out. 2012. 
RATTON, José Luiz. Megaeventos esportivos, violência e pânico moral: breves considerações sociológicas. Coletiva, n. 8, abr.-maio-jun. 2012.

ROCHE, Maurice. Mega-events and modernity: Olympics and Expos in the Growth of Global Culture. New York: Routledge, 2000.

RODRIGUES, Rejane Penna; PINTO, Leila Mirtes de Magalhães. Subsídios para pensar os legados de megaeventos esportivos em seus tempos presente, passado e futuro. In: RODRIGUES, Rejane Penna et al. (Org.). Legados de megaeventos esportivos. Brasília: Ministério do Esporte, 2008, p. 21- 25.

RUBIO, Katia. O legado educativo dos megaeventos esportivos. Motrivivência, v. 2, n. 32/33, p. 71-88, jun.-dez. 2009.

RUBIO, Katia. Os Jogos Olímpicos e a transformação das cidades: os custos sociais de um megaevento. Revista electrónica de geografía y ciencias sociales, v. IX, n. 194 (85), ago. 2005.

SILVA, Cinthia Lopes da. Legados de megaeventos esportivos: perdas e ganhos para a educação física escolar. In: MARCELLINO, Nelson Carvalho. (Org.). Legados de megaeventos esportivos. Campinas: Papirus, 2013.

SILVA, Silvio Ricardo da. CAMPOS, Priscila Augusta Ferreira. Futebol e Educação Física na escola: possibilidades de uma relação educativa. Ciência e cultura, v. 66, n. 2, jun. 2014.

SILVA, Silvio Ricardo da; SOUZA NETO, Georgino Jorge de; CAMPOS, Priscila Augusta Ferreira. Lazer, torcidas e futebol. In: ISAYAMA, H. F.; SILVA, Silvio Ricardo da. Estudos do lazer: um panorama. Rio de Janeiro, Apicuri, 2011, p. 111-123.

SOUZA NETO, Georgino Jorge de. A invenção do torcer em Bello Horizonte: da assistência ao pertencimento clubístico (1904-1930). Dissertação (Mestrado em Lazer) - Programa de Mestrado em Lazer, Escola de Educação Física e Terapia Ocupacional, UFMG, Belo Horizonte, 2010.

TAVARES, Otávio. Megaeventos esportivos. Movimento, v. 17, n. 3, p. 11-35, jul.-set. 2011.

VILLANO, Bernardo; SILVA, Dirce Maria Corrêa da; RIZZUTI, Elaine; MIRAGAIA, Ana Maria; COSTA, Lamartine Pereira da. Gestão de legados de megaeventos esportivos: pontos de convergência. In: RODRIGUES, Rejane Penna et al. (Org.). Legados de megaeventos esportivos. Brasília: Ministério do Esporte, 2008, p. 47-50.

Recebido para publicação em: 01 ago. 2018. Aprovado em: 01 nov. 2018. 